\section{Effects of Plant Activity on Mental Stress in Young Adults}

\author{
Ahmad Hassan, Chen Qibing ${ }^{1}$, Jiang Tao, Lv Bing-Yang, Li Nian, \\ Shu Li, Li Yu Tng, Jun Zhuo Li, and Shang Guan Ziyue \\ College of Landscape Architecture, Sichuan Agricultural University, Chengdu, \\ Sichuan 611130, China
}

\author{
Muhammad Sohaib Tahir \\ School of Electronics, Information and Electrical Engineering, Shanghai \\ Jiao Tong University, Shanghai 201100, China
}

Additional index words. horticultural, technology, blood pressure, brainwaves

\begin{abstract}
Advancements in electronic devices have led to increases in mental stress in modern adults, and removing this stress is crucial for mental health. The purpose of this study is to examine the psychophysiological benefits of contact with indoor plants. The effects of transplanting plants (horticultural activity) and work on a mobile phone (control activity) were assessed by blood pressure measurement, electroencephalography (EEG), the semantic differential method (SDM), and the State-Trait Anxiety Inventory (STAI). The SDM data showed that the subjects felt more relaxed, comfortable and natural, and experienced lower anxiety after the transplantation of plants than the control group. Participant's total alpha and beta wave mean values increased over time during the transplantation task but decreased at the end of the control task. The mean meditation score was significantly higher after transplanting plants. Our study results indicate that contact with plants may minimize mental stress.
\end{abstract}

The human relationship with nature is profoundly complex (Heynen et al., 2006; Jackson, 2003; Kahn, 2005; Kellert, 2004; Kibert, 1999; Miller, 2005) and therefore difficult to understand. However, extraordinary psychological, ecological, biological, and psychiatric research on this relationship has recently been performed. Many scientists have concluded that humans depend on nature for their physical, spiritual, psychological, and emotional needs (Friedmann and Thomas, 1995; Frumkin, 2001; Katcher and Beck, 1987; Roszak et al., 1995; St Leger, 2003; Wilson, 1984). Recent studies have reported that urban environments are unsuitable locations for humans (Bagot, 2005; Kellert, 1993; van den Berg et al., 2007). Most importantly, modern social environments have changed from the outdoors to indoors. More than $95 \%$ of an individual's daily activities occur indoors (Lee et al., 2015). Furthermore, developments in electronic technology have made it attractive for people to connect and remain connected to a machine environment. However, rapid technological developments have resulted in a new era with fewer "green" and more artificial surroundings. The widespread use of technology is associated with psychiatric comorbidities including internet addiction, depression, anxiety, and attention deficit and hyperactivity disorder (ADHD) in humans (Ho et al., 2014). In addition, the widespread use of mobile phones among younger generations

Received for publication 31 Aug. 2017. Accepted for publication 16 Nov. 2017.

1CCorresponding author. E-mail: cqb@sicau.edu.cn. has opened the door to new lifestyles and cultural pride (Reyns et al., 2013). Most college students spend their time studying online. Internet or online learning has become an indispensable tool for university students. The pooled prevalence of internet addiction among university students is $\approx 5$ times that in the general population (Zhang et al., 2017a). Previous studies have reported that excessive mobile phone usage could affect the brain and its normal activities (Imamura et al., 2009) and could increase the risk of internet addiction (Lai et al., 2013). Internet addictive behavior is common among adolescents worldwide. In Asia, the overall prevalence of smartphone ownership by adolescents is $62 \%$, ranging from $41 \%$ in China to $84 \%$ in South Korea (Mak et al., 2014b). Participation in online gaming ranges from $11 \%$ in China to $39 \%$ in Japan (Mak et al., 2014b). The prevalence rates of problematic internet use and internet addiction among adolescents are highest in Vietnam (21.2\%) (Tran et al., 2017b) and the Philippines (21\%) (Mak et al., 2014b). Excessive smartphone use and internet addiction are associated with poor health outcomes (Mak et al., 2014a), a lower quality of life (Tran et al., 2017b), impaired interpersonal relationships (Tran et al., 2017a), and sleep problems (Zhang et al., 2017b). Males are more affected than females, and $\approx 20 \%$ to $25 \%$ of these cases relate to the excessive use of mobile phones (World Health Organization, 2004). Indeed, the stressful and fast-paced modern lifestyle has strengthened the need for peaceful greener environments for relaxation (Stone, 2006). Although rapidly advancing technology will likely further contribute to the negative effects of the modern lifestyle, human development has experienced few changes during evolution over the past 10,000 years. For example, our genetic makeup has changed by only $0.005 \%$ (Williams and Nesse, 1991). Furthermore, peaceful green environments may represent part of the solution to this problem (Bird, 2007; Lee et al., 2009; Wendel et al., 2008). In recent years, the beneficial effect of green environments has been identified, and further environmental studies are under way (Kahn et al., 2009). Physical interactions with plants represent an emotional and silent act that can provide mental stability and comfort in different ways. Interaction with plants can also promote the health of office workers (Dravigne et al., 2008) by minimizing psychological stress (Kaplan, 2001), improving mood (Adachi et al., 2000; Shibata and Suzuki, 2001; Ulrich, 1981; Ulrich et al., 1991), and increasing mental efficiency (Cimprich, 1993; Hartig et al., 1991; Tennessen and Cimprich, 1995).

\section{Basic Knowledge of}

Electroencephalography and Brainwaves

In recent decades, neuroscience research has advanced and can presently provide a more in-depth understanding of brain activity. In 1875, Richard Caton discovered the presence of electrical currents in the human brain. In 1924, German scientist Hans Berger recorded electrical activity in the brain using EEGs (Teplan, 2002). In 1934, Adrian and Matthews devised the novel concept, of human brain waves. During the 1950s, EEG technology was successfully applied to all fields of cognitive science, neurology, and neurosurgery (Ali, 2012). Then, in 1964, Dr. Grey Walter connected electrodes directly to the motor areas of the human brain to record brainwave activity. An EEG is a recording of the electrical activity of the human brain at the scalp level (Stadelmann et al., 2013). EEG signals are generated from hyperpolarizing and depolarizing postsynaptic potentials in populations of pyramidal neurons (Jackson and Bolger, 2014; Sowndhararajan and Kim, 2016). Practical applications of EEGs include recordings of structural brain diseases, brain death, and dementia. In addition, EEGs are also used to control psychological disorders. The NeuroSky MindWave EEG headset is an innovative technique for recording live human brain activity. A practical application of this headset was launched in 2009 to control for ADHD and stress issues in humans, with $86 \%$ accurate results (Mostow et al., 2011). Brainwaves typically appear during both resting and active states. Our behaviors, thoughts, and emotions are reflections of electrical activity inside the brain. An EEG measures these electrical changes and presents them as waves. The EEG signals are divided into different waves, such as alpha, beta, delta, theta, and gamma waves in the frequency ranges of $8-13 \mathrm{~Hz}, 13-30 \mathrm{~Hz}, 0-4$ $\mathrm{Hz}, 4-8 \mathrm{~Hz}$, and $>30 \mathrm{~Hz}$, respectively(Desai et al., 2015). Research has shown that 
physical activity with plants can be effective against certain diseases and mental stress (Lee et al., 2015; Salovey et al., 2000), although the exact mechanism is unknown. Furthermore, the therapeutic effects of plants have not been properly researched, and few studies have performed physiological and psychological analysis regarding plants. The objective of this study is to examine the physiological and psychological benefits of contact with plants in modern adults. We concentrate on brainwave changes when a subject has contact with plants, and we record the subject's electrical brainwave activity. Furthermore, we also attempt to investigate the psychological changes during a subject's association with plants.

\section{Materials and Methods}

Experimental location. This indoor experiment was conducted in a laboratory at Sichuan Agricultural University in Sept. 2016. One room with white walls was selected with two windows on the south side. The room was ventilated and kept silent to ensure that the students were free from outside interference. The room was $\approx 8 \mathrm{~m}$ long, $5 \mathrm{~m}$ wide, and $4 \mathrm{~m}$ high. All of the measuring devices were placed behind the participants to avoid any disturbance during the experiment. The experiment was performed during the day under the controlled temperature, humidity, and lightintensity conditions of $24{ }^{\circ} \mathrm{C}, 50 \%$ relative humidity, and $500 \mathrm{~lx}$, respectively.

Participants. We enrolled 50 volunteer male and female university students experiencing high academic stress (mean age 19.6士 1.42 years; weight $51.7 \pm 7.21 \mathrm{~kg}$; height $161.6 \pm 4.2 \mathrm{~cm})$ from the horticulture department of Sichuan Agricultural University, China. Participants in this experiment were selected based on availability, and none of the participants had a history of physical or mental disorders. Before starting the experiments, a full explanation of the research was provided and informed consent was obtained from all participants. This experiment was arranged with the approval of the local Ethics Committee for the College of Landscape Architecture, Sichuan Agricultural University, China.

Materials. A general horticultural practice (transplanting plants) that uses real soil and indoor plants for $15 \mathrm{~min}$ was selected, and a game involving downloading a difficult app, one of the most common mobile phone tasks that required constant physical activity similar to the transplanting activity, was used as a control task for $15 \mathrm{~min}$. Before the start of the experiments, brief instructions were presented to the participants. The experimental method was taught to each subject before the experiments. Indoor plants of almost equal size were used for transplantation, with each volunteer using their hands. Plastic containers $(\approx 3-5 \mathrm{~mm}$ in diameter) were used for the transplanting activity. Both tasks were performed on a large table in a standing position for $15 \mathrm{~min}$, against a wall coated with black paper. The detailed test procedure is shown in Fig. 1.
Protocol. The subjects were divided into two groups. On the first day of the experiments, group A $(N=25)$ conducted the horticultural task (transplanting plants), whereas group $\mathrm{B}(N=25)$ performed the control task. On the second day, the groups switched tasks.

Measurements. First, the subjects were administered pretest questionnaires, which included their age, weight, and height. After the subjects completed the pretest questionnaires, a Mind Wave EEG headset was attached to the subjects' heads and the subjects were then moved to the experimental room. After resting for $5 \mathrm{~min}$, each subject's blood pressure was measured, and they then performed the given tasks for $15 \mathrm{~min}$. The subjects' EEGs were continuously measured using a NeuroSky Mind Wave EEG headset for 15 min during each activity. The headset records brainwaves from the Fp1 position above the eye. The headset consists of four essential parts: 1) a headband, 2) an ear clip, 3) a sensor arm that contains the EEG electrode, and 4) a Bluetooth device (Sałabun, 2014). The headset receives brainwave signals in the form of attention and meditation (Crowley et al., 2010; Sałabun, 2014). Blood pressure data were obtained before and after the experiment using a sphygmomanometer (Omron HEM7011, Omron, China), and at the end of the
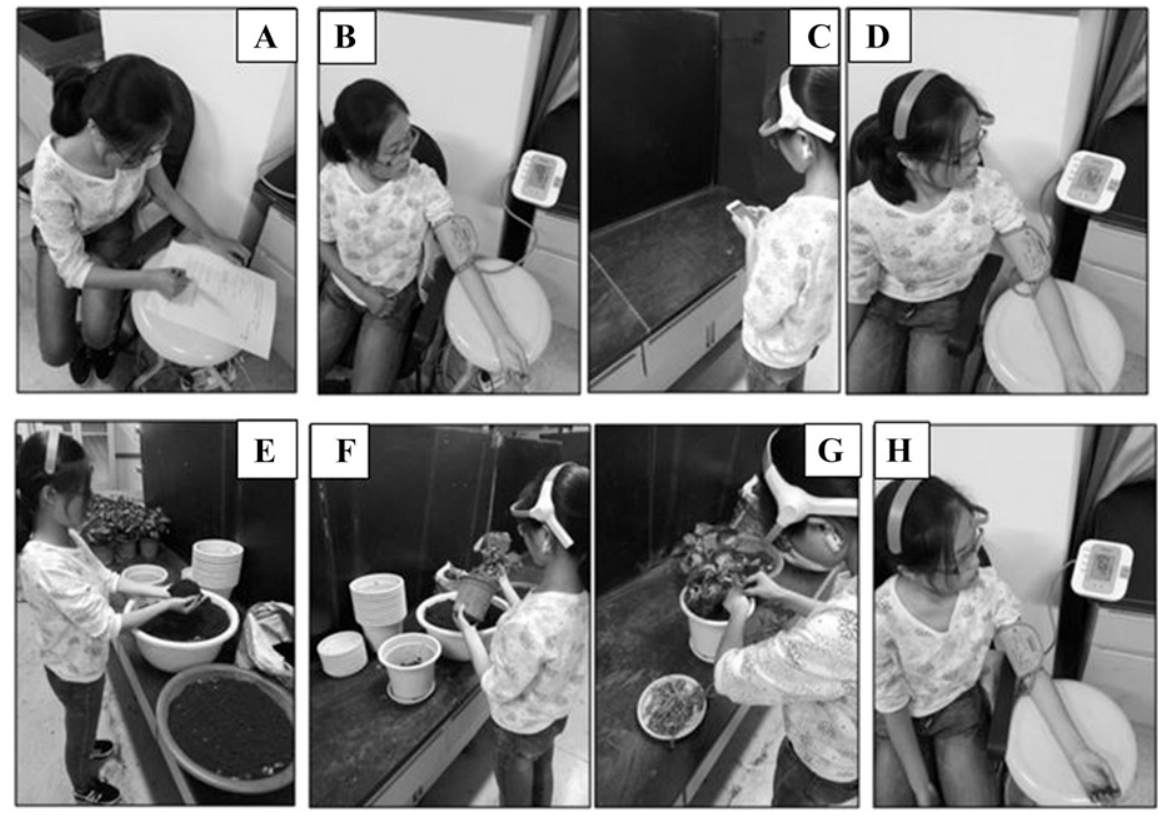

Fig. 1. Photographs of experimental procedures: (A) a subject completing a questionnaire form; (B) preblood pressure measurement; (C) a subject performing the control task; (D) blood pressure measurement after the control task; $(\mathbf{E}-\mathbf{G})$ a subject transplanting indoor plants; $(\mathbf{H})$ blood pressure measurement after transplanting indoor plants.

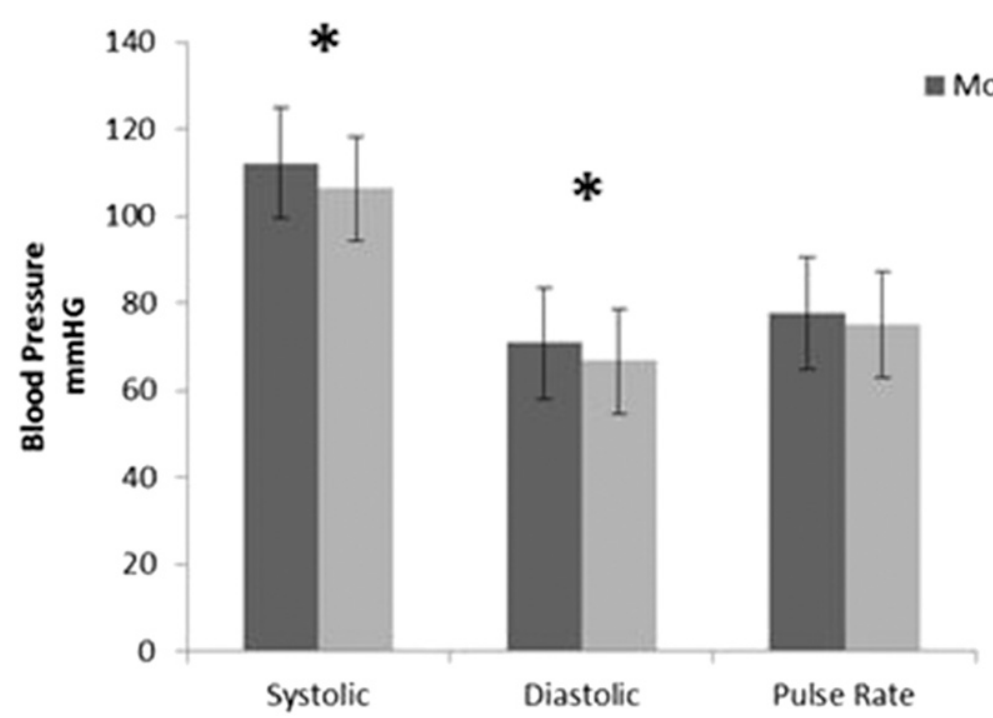

Fig. 2. Comparison of blood pressure values after the transplanting and control tasks. $N=50$; mean $\pm \mathrm{SD}$; $* P<0.05$; paired $t$ test. 
experiment, the subjects completed the psychological questionnaires.

Data analysis. The brainwaves (high alpha and high beta) and the meditation scores, which were collected at 1-min intervals for each experimental task, were compared based on an average of $15 \mathrm{~min}$. According to the eSense Metric, the attention and meditation data were scaled from 1 to 100 (40-60, natural state; 60-80, slightly high; 80-100, very high; $20-40$ slightly low; and 0-20, very low) (Sałabun, 2014; Sezer et al., 2017). The eSense Attention meter measured the intensity of each participant's level of mental "attention" or "focus" to determine the level of concentration, whereas the eSense Meditation meter recorded the active mental processes within the brain and indicated the intensity of each participant's level of mental "relaxation" or "calmness." The STAI (Hidano et al., 2000) and the SDM (Suci and Tannenbaum, 1957) were both used to control the psychological responses after each task.

Statistical analysis. Statistical analyses were performed using SPSS 16.0 (SPSS Inc., Chicago, IL). A paired $t$ test was used to analyze the mean values of the physiological data, and the threshold for statistical significance was set at $P<0.05$. A Wilcoxon signed-rank test was used to analyze the mean values of the psychological data, with significance set at $P<0.01$.

\section{Results}

We confirmed that significant differences in blood pressure occurred between the two groups. The participants' systolic and diastolic blood pressure values $(\mathrm{mmHg})$ significantly decreased after the transplanting task compared with those measured after the control task. In addition, no significant changes were observed in the pulse rate (Fig. 2). The subjects presented greater fluctuations in brainwave patterns (high alpha and high beta) after the transplanting task than after the control task. In the 1-min analysis, most of the alpha (power units) values increased during the transplanting task compared with those measured during the control task (Fig. 3A). The mean alpha (power units) over the entire transplanting task significantly increased compared with that observed during the control task (plant, 28,873.7; mobile, 23,000.4; $P<0.05$, Fig. 3B).

\section{A}

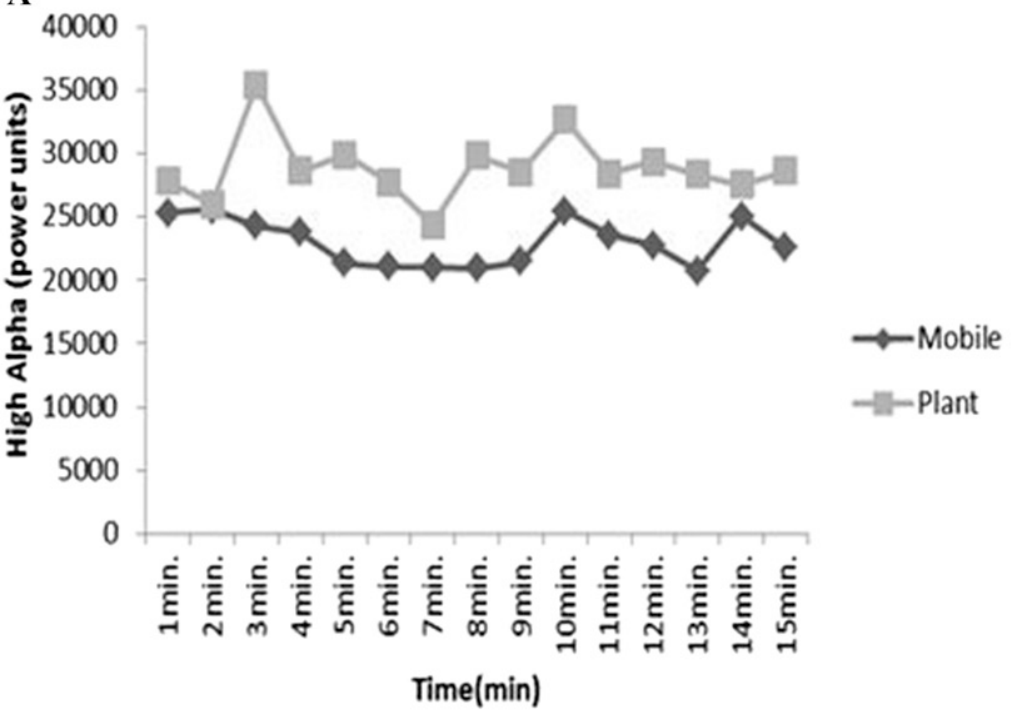

B

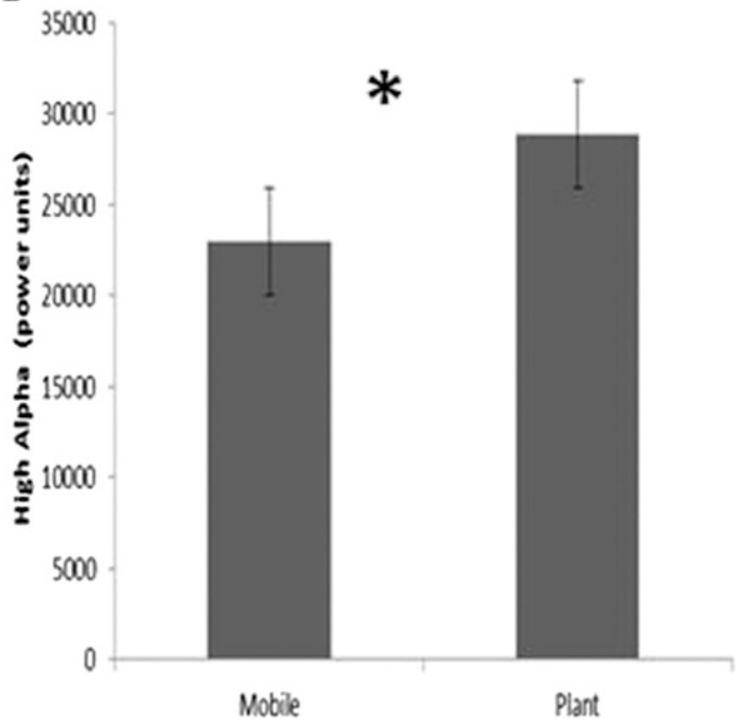

Fig. 3. One-minute averages and the overall mean high-alpha wave (power units) values during the transplanting and control tasks. (A) Change in each 1-min highalpha wave (power units) value; (B) overall mean high-alpha wave (power units) values. $N=50$; mean $\pm \mathrm{SD}$; ${ }^{*} P<0.05$; paired $t$ test.

A

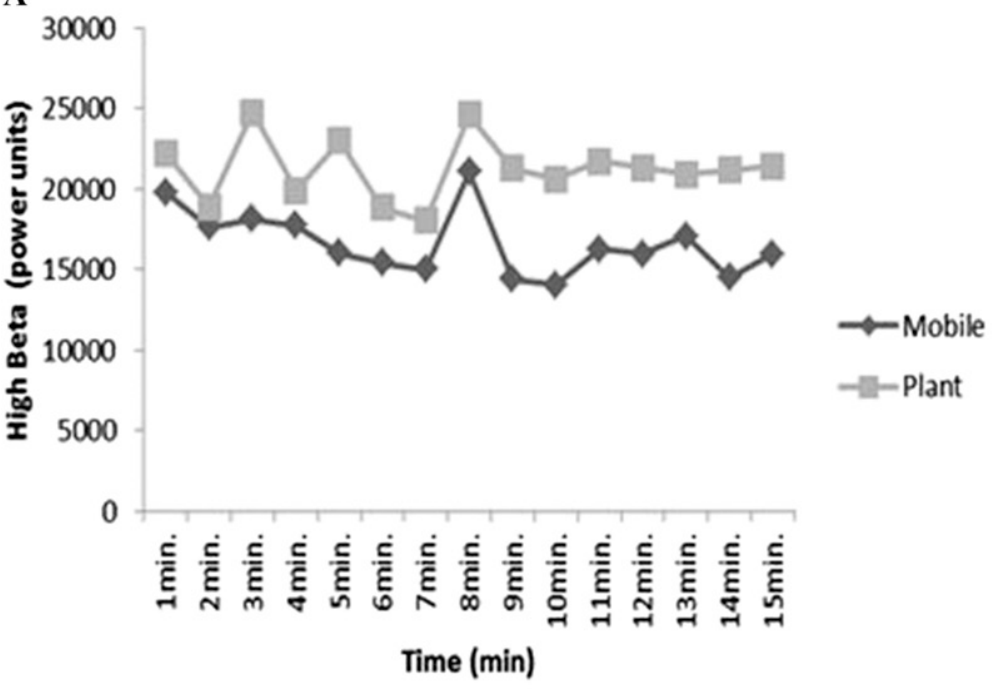

B

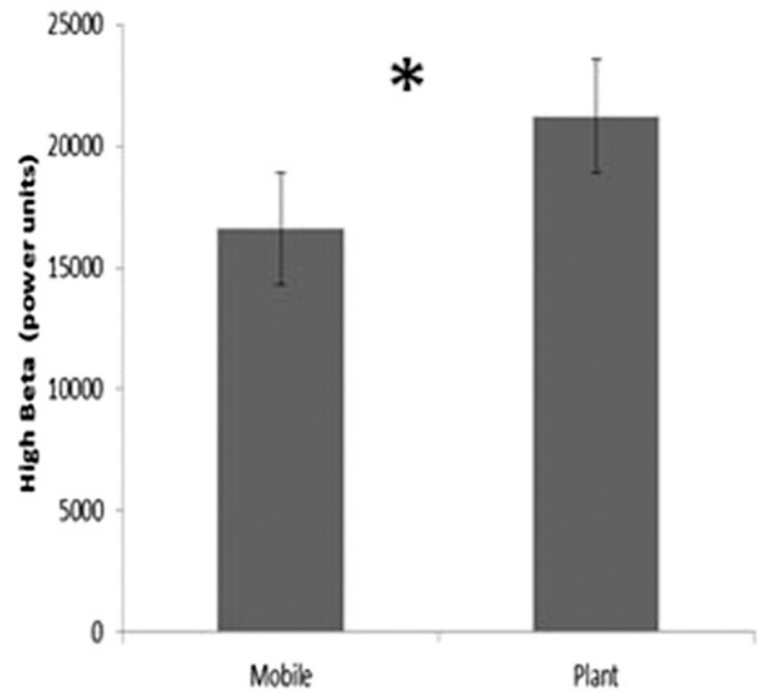

Fig. 4. One-minute averages and the overall mean high-beta wave (power units) values during the transplanting and control tasks. (A) Change in each 1-min beta wave (power units) value; (B) overall mean high-beta wave (power units) values. $N=50$; mean $\pm \mathrm{SD}$; $P<0.05$; paired $t$ test. 
Similarly, in the 1-min analysis, most of the beta (power units) values increased during the transplanting task compared with those measured during the control task (Fig. 4A). The mean beta (power units) over the entire transplanting task significantly increased compared with that of the control task (plant, 21,234.2; mobile, 16,589.7; $P<0.05$; Fig. 4B). The participants' mean meditation (relaxation) scores were also different after the two tasks. The NeuroSky MindWave EEG headset indicated that the participants' mean relaxation level significantly increased after the transplanting task compared with that after the control task (plant, $50.5 \pm 10.12$; control, $38.93 \pm 11.68, P<0.002$, Fig. 5). From Fig. 5, we can see that when the participants performed the horticultural activity, their relaxation level increased, which suggests that the participants were happy and relaxed. However, in the control group, the relaxation level decreased, suggesting that the participants may have felt bored or stressed. The SDM and STAI questionnaires, which were completed after both tasks, showed differences between the two environments. The participants' mean anxiety scores significantly decreased after the transplanting task compared with those after the control task (plant, 33.3; control, 38.2; $P$ $<0.01$; Fig. 6). Moreover, the participants felt more relaxed, comfortable, and natural after performing the transplanting task than after the control task $(P<0.01$, Fig. 7$)$.

\section{Discussion}

We investigated the stress-reducing effects of 15-min horticultural activity by analyzing the physiological and psychological responses of the participants. Based on the earlier findings, the blood pressure measurements of the participants were significantly reduced during the transplanting task compared with those obtained during the control task. Similar results were obtained from a previous study in which participants transplanted indoor plants (Lee et al., 2015). The human brain consists of the sympathetic and parasympathetic nervous systems, and both systems control human activities continuously. The sympathetic nervous system is involved in emotional activities, such as galvanic skin responses and heart rate, and controls increases in blood pressure, whereas the parasympathetic nervous system is associated with decreases in blood pressure ( $\mathrm{Li}$ et al., 2012). The EEG scan represents a new scientific approach for monitoring human stress and shows variations in standard brain wave patterns caused by external environments (Jing and Takigawa, 2000). The results of the participants' high-alpha and high-beta brainwaves indicated a positive impact of plants on mental stress, which decreased when a person was exposed to a stressor. The participants' higher alpha waves indicated a stress-reducing effect after 15 min of the transplanting task. Thus, the increase in alpha waves in the transplantation

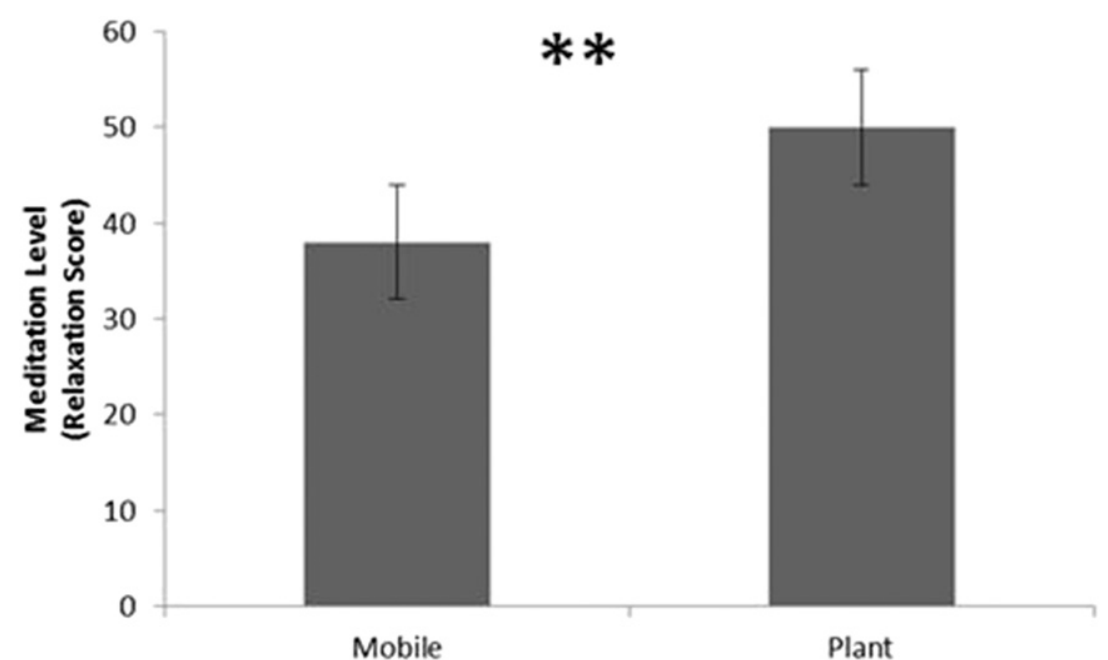

Fig. 5. Subjects' overall mean meditation scores after the transplanting and control tasks. $N=50$; mean \pm $\mathrm{SD} ; * * P<0.05$; paired $t$ test.

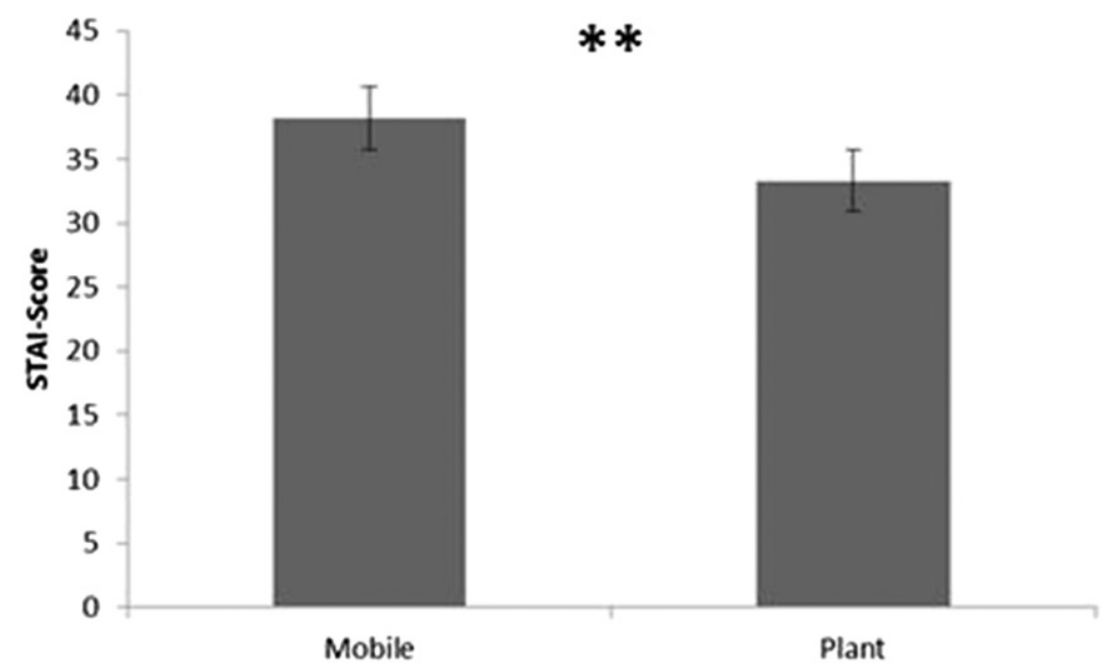

Fig. 6. Comparison of participants' State-Trait Anxiety Inventory scores between the transplanting and control tasks. $N=50$; mean $\pm \mathrm{SD} ; * * P<0.01$, Wilcoxon signed-rank test.

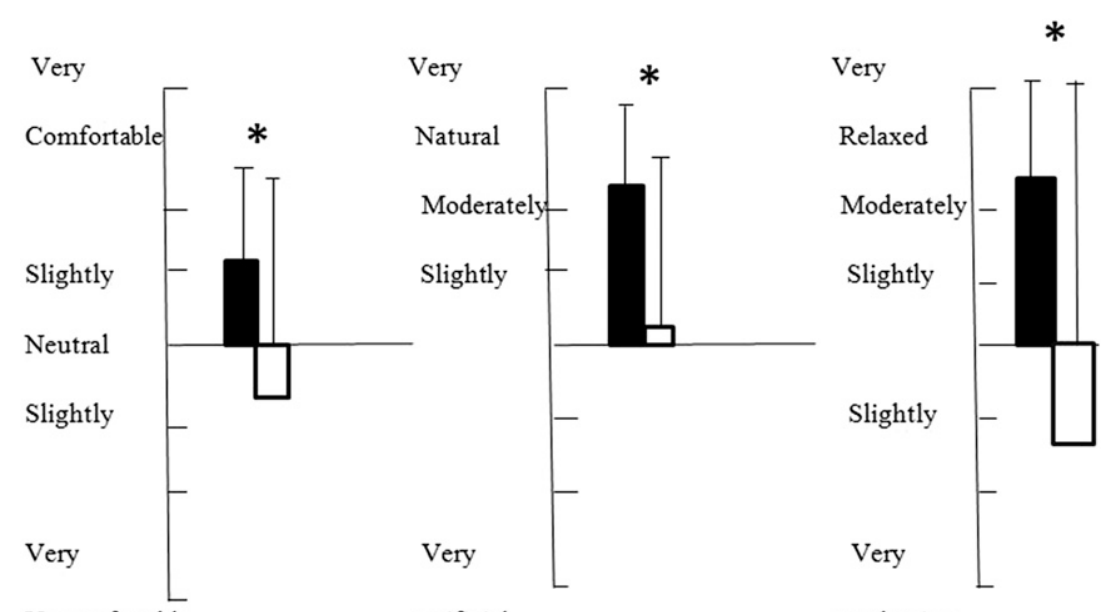

Uncomfortable

artificial

awakening 
group indicated that relaxation increased during this task (Başar, 2012; Neuper and Pfurtscheller, 2001), "whereas" the lower alpha waves in the control group indicated that the participants experienced stress during this task. Alpha waves are associated with a reduction in stress and an increased ability to recall memories (Nomura et al., 2006; Williams, 2001; Williams et al., 2006). Antianxiety medication such as benzodiazepine also reduces alpha activity (Puri et al., 2013). It is interesting to note that horticultural activity has demonstrated similar effects as anxiolytic medications. Previous studies have reported that alpha waves are linked to relaxed wakefulness (Klemm, 1966). In addition, increases in theta and alpha power are observed in relaxation (Jacobs and Friedman, 2004; Lagopoulos et al., 2009; Stigsby et al., 1981; Tebetcis, 1975). Studies have reported that alpha power increases when there is a feeling of happiness. In contrast, alpha power decreases when there is a feeling of sadness (Kostyunina and Kulikov, 1996). "Interestingly, humans begin producing alpha waves immediately before falling asleep and after waking in the morning" (Hobson, 1969). Certain plants, such as cannabis, also affect alpha brainwaves, which is why cannabis users adversely produce alpha waves (Struve et al., 2003). Similarly, the participants' beta wave activity was enhanced after 15 min during the transplanting task. This finding indicates that relaxation and the concentration level of the transplantation group increased, and their mental acuity was higher than that of the control group. An increase in beta power during relaxation has been reported (Vijayalakshmi et al., 2010). Beta waves are usually associated with strong emotions, such as excitement, attention, and concentration (Neuper and Pfurtscheller, 2001). Heightened mental acuity and concentration have been observed as cases of higher beta waves (Neuper and Pfurtscheller, 2001). Moreover, low beta wave activity can cause considerable emotional swings (insomnia) (Hauri, 1981). Beta waves dominate when focus is directed toward mental tasks and during an alert. In contrast, beta waves decrease during drowsiness (Lee et al., 2014). Beta waves naturally appear during various tasks, such as engaging in deep conversations, playing sports, listening to speeches, and attending lectures in a classroom (Cavanna and Trimble, 2006). The participants' SDM and STAI results also indicated that their interactions with plants had positive effects on mental stress and that the control task had a negative effect on mental stress.

\section{Conclusion}

Our study provides scientific evidence that contact with plants rather than performing mental tasks can minimize psychological and physiological stress by lowering blood pressure, increasing comfort, creating a "natural environment," and promoting relaxation, and may also lead to lower anxiety. However, there are a few limitations of this study; for example, our participant group was limited to young male and female university students; more diversified groups with different plants, nationalities, and methodologies should be tested in the future.

\section{Literature Cited}

Adachi, M., C. Rohde, and A. Kendle. 2000 Effects of floral and foliage displays on human emotions. HortTechnology 10:59-63.

Ali, M.Z. 2012. EEG-based assessment of driver's cognitive response in virtual traffic light environment. Lamar Univ., Beaumont, TX.

Bagot, K. 2005. The importance of green play spaces for children: Aesthetic, athletic and academic. J. Victorian Assn. Environ. Educ. 28:12-16.

Başar, E. 2012. A review of alpha activity in integrative brain function: Fundamental physiology, sensory coding, cognition and pathology. Intl. J. Psychophysiol. 86:1-24.

Bird, W. 2007. Natural greenspace. Brit. J. Gen. Pract. 57:69.

Cavanna, A.E. and M.R. Trimble. 2006. The precuneus: A review of its functional anatomy and behavioural correlates. Brain 129:564583.

Cimprich, B. 1993. Development of an intervention to restore attention in cancer patients. Cancer Nurs. 16:83-92.

Crowley, K., A. Sliney, I. Pitt, and D. Murphy. 2010. Evaluating a brain-computer interface to categorise human emotional response. IEEE International Conference on Advanced Learning Technologies, Tunisia, 5-7 July 2010.

Desai, R., A. Tailor, and T. Bhatt. 2015. Effects of yoga on brain waves and structural activation: A review. Complement. Ther. Clin. Pract. 21:112-118.

Dravigne, A., T.M. Waliczek, R. Lineberger, and J. Zajicek. 2008. The effect of live plants and window views of green spaces on employee perceptions of job satisfaction. HortScience 43:183-187.

Friedmann, E. and S.A. Thomas. 1995. Pet ownership, social support, and one-year survival after acute myocardial infarction in the Cardiac Arrhythmia Suppression Trial (CAST). Amer. J. Cardiol. 76:1213-1217.

Frumkin, H. 2001. Beyond toxicity: Human health and the natural environment. Amer. J. Prev. Med. 20:234-240.

Hartig, T., M. Mang, and G.W. Evans. 1991 Restorative effects of natural environment experiences. Environ. Behav. 23:3-26.

Hauri, P. 1981. Treating psychophysiologic insomnia with biofeedback. Arch. Gen. Psychiatry 38:752-758.

Heynen, N.C., M. Kaika, and E. Swyngedouw 2006. In the nature of cities: Urban political ecology and the politics of urban metabolism. Taylor \& Francis, Abingdon, UK.

Hidano, N., M. Fukuhara, M. Iwawaki, S. Soga, and C.D. Spielberger. 2000. State-trait anxiety inventory-form JYZ. Japan UNI Agency, Tokyo, Japan.

Ho, R.C., M.W.B. Zhang, T.Y. Tsang, A.H. Toh, F. Pan, Y. Lu, C. Cheng, P.S. Yip, L.T. Lam, C-M Lai, H. Watanabe, and K-K. Mak. 2014. The association between internet addiction and psychiatric co-morbidity: A meta-analysis. BMC Psychiatry 14:183.

Hobson, J.A. 1969. A manual of standardized terminology, techniques and scoring system for sleep stages of human subjects. In: A.
Rechtschaffen and A. Kales (eds.). Public Health Service, U.S. Government Printing Office, Washington, DC.

Imamura, A., A. Nishida, N. Nakazawa, S. Shimodera, G. Tanaka, H. Kinoshita, H. Ozawa, and Y. Okazaki. 2009. Effects of cellular phone email use on the mental health of junior high school students in Japan. Psychiatry Clin. Neurosci. 63:703.

Jackson, A.F. and D.J. Bolger. 2014. The neurophysiological bases of EEG and EEG measurement: A review for the rest of us. Psychophysiology 51:1061-1071.

Jackson, L.E. 2003. The relationship of urban design to human health and condition. Landsc. Urban Plan. 64:191-200.

Jacobs, G.D. and R. Friedman. 2004. EEG spectral analysis of relaxation techniques. Appl. Psychophysiol. Biofeedback 29:245-254.

Jing, H. and M. Takigawa. 2000. Topographic analysis of dimension estimates of EEG and filtered rhythms in epileptic patients with complex partial seizures. Biol. Cybern. 83:391397.

Kahn, P.H. 2005. Encountering the other. Child. Youth Environ. 15:392-397.

Kahn, P.H., R.L. Severson, and J.H. Ruckert. 2009 The human relation with nature and technological nature. Curr. Dir. Psychol. Sci. 18:37-42.

Kaplan, R. 2001. The nature of the view from home. Environ. Behav. 33:507-542.

Katcher, A.H. and A.M. Beck. 1987. Health and caring for living things. Anthrozoos 1:175-183.

Kellert, S. 2004. Ordinary nature: The value of exploring and restoring nature in everyday life, p. 9-19. In: W.W. Shaw, L.K. Harris, and L. Vandruff (eds.). 4th International Urban Wildlife Symposium. Univ. Arizona, Tucson, AZ.

Kellert, S.R. 1993. The biological basis for human values of nature, p. 42-69. In: S.R. Kellert and E.O. Wilson (eds.). The biophilia hypothesis. Island Press, Washington, DC.

Kibert, C.J. 1999. Reshaping the built environment: Ecology, ethics, and economics. Island Press, Washington, DC

Klemm, W.R. 1966. Electroencephalographicbehavioral dissociations during animal hypnosis. Electroencephalogr. Clin. Neurophysiol. 21:365-372.

Kostyunina, M.B. and M.A. Kulikov. 1996. Frequency characteristics of EEG spectra in the emotions. Neurosci. Behav. Physiol. 26:340-343.

Lagopoulos, J., J. Xu, I. Rasmussen, A. Vik, G.S. Malhi, C.F. Eliassen, I.E. Arntsen, J.G. Sæther, S. Hollup, A. Holen, S. Davanger, and Ø. Ellingsen. 2009. Increased theta and alpha EEG activity during nondirective meditation. J. Altern. Complement. Med. 15:1187-1192.

Lai, C.M., K.K. Mak, H. Watanabe, R.P. Ang, J.S Pang, and R.C.M. Ho. 2013. Psychometric properties of the internet addiction test in Chinese adolescents. J. Pediatr. Psychol. 38:794-807.

Lee, B-G., B-L. Lee, and W-Y. Chung. 2014 Mobile healthcare for automatic driving sleep-onset detection using wavelet-based EEG and respiration signals. Sensors (Basel) 14:17915-17936.

Lee, J., B-J. Park, Y. Tsunetsugu, T. Kagawa, and Y. Miyazaki. 2009. Restorative effects of viewing real forest landscapes, based on a comparison with urban landscapes. Scand. J. For. Res. 24:227-234.

Lee, M-S., J. Lee, B-J. Park, and Y. Miyazaki. 2015. Interaction with indoor plants may reduce psychological and physiological stress by suppressing autonomic nervous system activity 
in young adults: A randomized crossover study. J. Physiol. Anthropol. 34:21.

Li, X., Z. Zhang, M. Gu, D-Y. Jiang, J. Wang, Y-M. Lv, Q-X. Zhang, and H-T. Pan. 2012. Effects of plantscape colors on psycho-physiological responses of university students. J. Food. Agr. Environ. 10:702-708.

Mak, K-K., C-M. Lai, C-H. Ko, C. Chou, D-I. Kim, H. Watanabe, and R.C.M. Ho. 2014a. Psychometric properties of the Revised Chen Internet Addiction Scale (CIAS-R) in Chinese adolescents. J. Abnorm. Child Psychol. 42:12371245.

Mak, K-K., C-M. Lai, H. Watanabe, D-I. Kim, N. Bahar, M. Ramos, K.S. Young, R.C.M. Ho, N-R. Aum, and C. Cheng. 2014b. Epidemiology of internet behaviors and addiction among adolescents in six Asian countries. Cyberpsychol. Behav. Soc. Netw. 17:720-728.

Miller, J.R. 2005. Biodiversity conservation and the extinction of experience. Trends Ecol. Evol. 20:430-434

Mostow, J., K-M. Chang, and J. Nelson. 2011. Toward exploiting EEG input in a reading tutor, p. 230-237. In: G. Biswas, S. Bull, J. Kay, and A. Mitrovic (eds.). 15th International Conference on Artificial Intelligence in Education. Springer, Berlin, Germany.

Neuper, C. and G. Pfurtscheller. 2001. Event-related dynamics of cortical rhythms: Frequencyspecific features and functional correlates. Intl. J. Psychophysiol. 43:41-58.

Nomura, T., K. Higuchi, H. Yu, S-I. Sasaki, S. Kimura, H. Itoh, M. Taniguchi, T. Arakawa, and K. Kawai. 2006. Slow-wave photic stimulation relieves patient discomfort during esophagogastroduodenoscopy. J. Gastroenterol. Hepatol. 21:54-58.

Puri, B., A. Hall, and R. Ho. 2013. Revision notes in psychiatry. 3rd ed. CRC Press, New York, NY.

Reyns, B.W., M.W. Burek, B. Henson, and B.S. Fisher. 2013. The unintended consequences of digital technology: Exploring the relationship between sexting and cybervictimization. J. Crim. Justice 36:1-17.

Roszak, T.E., M.E. Gomes, and A.D. Kanner. 1995. Ecopsychology: Restoring the earth, healing the mind. Sierra Club Books, San Francisco, CA.

Sałabun, W. 2014. Processing and spectral analysis of the raw EEG signal from the MindWave. Przeglad Elektrotechniczny 90:169-174.
Salovey, P., A.J. Rothman, J.B. Detweiler, and W.T. Steward. 2000. Emotional states and physical health. Amer. Psychol. 55:110-121.

Sezer, A., Y. İnel, A.Ç. Seçkin, and U. Uluçınar. 2017. The relationship between attention levels and class participation of first-year students in classroom teaching departments. Intl. J. Instruction 10:55-68.

Shibata, S. and N. Suzuki. 2001. Effects of indoor foliage plants on subjects' recovery from mental fatigue. N. Amer. J. Psychol. 3:385.

Sowndhararajan, K. and S. Kim. 2016. Influence of fragrances on human psychophysiological activity: With special reference to human electroencephalographic response. Sci. Pharm. 84:724-751.

St Leger, L. 2003. Health and nature-New challenges for health promotion. Oxford Univ. Press, Oxford, UK.

Stadelmann, K., T.D. Latshang, C.M. Lo Cascio, N. Tesler, A-C. Stoewhas, M. Kohler, K.E. Bloch, R. Huber, and P. Achermann. 2013. Quantitative changes in the sleep EEG at moderate altitude $(1630 \mathrm{~m}$ and $2590 \mathrm{~m})$. PLoS One 8 : e76945.

Stigsby, B., J.C. Rodenberg, and H.B. Moth. 1981. Electroencephalographic findings during mantra mediation (transcendental meditation). A controlled, quantitative study of experienced meditators. Electroencephalogr. Clin. Neurophysiol. 51:434-442.

Stone, D. 2006. Sustainable development: Convergence of public health and natural environment agendas, nationally and locally. Public Health 120:1110-1113.

Struve, F.A., B.R. Manno, P. Kemp, G. Patrick, and J.E. Manno. 2003. Acute marihuana (THC) exposure produces a "transient" topographic quantitative EEG profile identical to the "persistent" profile seen in chronic heavy users. Clin. Electroencephalogr. 34:75-83.

Suci, G.J. and P.H. Tannenbaum. 1957. The measurement of meaning. Univ. Illinois, Urbana, IL.

Tebetcis, A.K. 1975. A controlled study of the EEG during transcendental meditation: Comparison with hypnosis. Psychiatry Clin. Neurosci. 29:305-313

Tennessen, C.M. and B. Cimprich. 1995. Views to nature: Effects on attention. J. Environ. Psychol. 15:77-85.

Teplan, M. 2002. Fundamentals of EEG measurement. Meas. Sci. Rev. 2:1-11.

Tran, B.X., L.T. Huong, N.D. Hinh, L.H. Nguyen, B.N. Le, V.M. Nong, V.T.M. Thuc, T.D. Tho,
C. Latkin, M.W.B. Zhang, and R.C.M. Ho. 2017a. A study on the influence of internet addiction and online interpersonal influences on health-related quality of life in young Vietnamese. BMC Public Health 17:138.

Tran, B.X., H.T. Mai, L.H. Nguyen, C.T. Nguyen, C.A. Latkin, M.W.B. Zhang, and R.C.M. Ho. 2017b. Vietnamese validation of the short version of internet addiction test. Addictive Behaviors Rpt. 6:45-50.

Ulrich, R.S. 1981. Natural versus urban scenes. Environ. Behav. 13:523-556.

Ulrich, R.S., R.F. Simons, B.D. Losito, E. Fiorito, M.A. Miles, and M. Zelson. 1991. Stress recovery during exposure to natural and urban environments. J. Environ. Psychol. 11:201230.

van den Berg, A.E., T. Hartig, and H. Staats. 2007. Preference for nature in urbanized societies: Stress, restoration, and the pursuit of sustainability. J. Soc. Issues 63:79-96.

Vijayalakshmi, K., S. Sridhar, and P. Khanwani. 2010. Estimation of effects of alpha music on EEG components by time and frequency domain analysis. International Conference on Computer and Communication Engineering (ICCCE), Kuala Lumpur, Malaysia, 11-12 May 2010.

Wendel, A.M., A.L. Dannenberg, and H. Frumkin. 2008. Designing and building healthy places for children. Intl. J. Environ. Health 2:338-355.

Williams, G.C. and R.M. Nesse. 1991. The dawn of Darwinian medicine. Qrtly. Rev. Biol. 66:1-22.

Williams, J., D. Ramaswamy, and A. Oulhaj. 2006. $10 \mathrm{~Hz}$ flicker improves recognition memory in older people. BMC Neurosci. 7:21

Williams, J.H. 2001. Frequency-specific effects of flicker on recognition memory. Neuroscience 104:283-286.

Wilson, E.O. 1984. Biophilia. Harvard Univ. Press, Cambridge, MA.

World Health Organization. 2004. Promoting mental health: Concepts, emerging evidence, practice: Summary report. World Health Organization, Geneva, Switzerland.

Zhang, M.W.B., R.B.C. Lim, C. Lee, and R.C.M. Ho. 2017a. Prevalence of internet addiction in medical students: A meta-analysis. Acad. Psychiatry, doi: 10.1007/s40596-017-0794-1.

Zhang, M.W.B., B.X. Tran, L.T. Huong, N.D. Hinh, H.L.T. Nguyen, T.D. Tho, C. Latkin, and R.C.M. Ho. 2017b. Internet addiction and sleep quality among Vietnamese youths. Asian J. Psychiatr. 28:15-20. 